\title{
Distinct Roles for Ceramide and Glucosylceramide at Different Stages of Neuronal Growth
}

\author{
Andreas Schwarz and Anthony H. Futerman \\ Department of Membrane Research and Biophysics, Weizmann Institute of Science, Rehovot 76100, Israel
}

Sphingolipids (SLs) are important structural and regulatory components of neuronal plasma membranes. Previous studies using fumonisin $B_{1}$, an inhibitor of the synthesis of ceramide, the precursor of all SLs, demonstrated that ceramide synthesis is required to sustain axonal growth in hippocampal neurons (Harel and Futerman, 1993; Schwarz et al., 1995) and dendritic growth in cerebellar Purkinje cells (Furuya et al., 1995). We now show that ceramide plays distinct roles at different stages of neuronal development. (1) During axon growth, ceramide must be metabolized to glucosylceramide (GlcCer) to sustain growth. Thus, whereas D-erythro-ceramide, which is metabolized to GlcCer, is able to antagonize the disruptive effects of fumonisin $\mathrm{B}_{1}$ on axon growth, L-threo-ceramide, which is not metabolized to GlcCer, is ineffective. (2) The formation of minor processes from lamellipodia can be stimulated by incubation with shortacyl chain analogs of ceramide that are active in ceramide- mediated signaling pathways, or by generation of endogenous ceramide by incubation with sphingomyelinase. However, GlcCer synthesis is not required for this initial stage of neuronal development. (3) During minor process formation and during axon growth, incubation with high concentrations of ceramide or sphingomyelinase, but not dihydroceramide, induces apoptosis. Together, these observations are consistent with the possibility that minor process formation and apoptosis can be regulated by ceramide-dependent signaling pathways and that the decision whether to enter these diametrically opposed pathways depends on intracellular ceramide concentrations. In contrast, axonal growth requires the synthesis of GlcCer from ceramide, perhaps to support an intracellular transport pathway.

Key words: membranes; sphingolipids; ceramide; glucosylceramide; axon growth; neuronal differentiation; apoptosis
Sphingolipids (SLs) are enriched in neuronal plasma membranes, although their precise functions in neurons are not known (Ledeen and Yu, 1992). To resolve this issue, we have initiated studies examining the effects of manipulating SL metabolism on neuronal development.

These studies have been performed with well characterized cultures of hippocampal neurons that develop by a stereotypic sequence of events (Dotti et al., 1988; Goslin and Banker, 1991), permitting analysis of the role of SLs in defined stages of development. In the initial stage of growth [stage 1, Dotti et al. (1988); see also Fig. 3 in this work], hippocampal neurons are characterized by the presence of many lamellipodia around the cell body that display intense pseudopodial activity. The second stage of development is marked by loss of lamellipodia and extension of a number of short processes, designated "minor processes" (stage 2, see Fig. 3). After some hours one of the minor processes starts to grow rapidly $(10-15 \mu \mathrm{m} / \mathrm{hr})$ and develops axonal characteristics (stage 3, see Fig. 3). Axons form branches as collaterals, and as each new branch emerges, the growth cone of the original axon loses its lamellipodial appearance and elongation stops (Dotti et al., 1988).

To date, most of our studies have focused on the role of SLs during axon growth (stage 3 ). We originally demonstrated that incubation with fumonisin $\mathrm{B}_{1}\left(\mathrm{FB}_{1}\right)$, a specific inhibitor of $N$-acylation of the sphingoid long chain bases dihydrosphingosine

\footnotetext{
Received Dec. 5, 1996; revised Feb. 4, 1997; accepted Feb. 10, 1997.

This work was supported by the German-Israel Foundation for Scientific Research and Development. A.H.F. is the incumbent of the Recanati Career Development Chair in Cancer Research. We thank Rivi Zisling for expert help in preparing and maintaining hippocampal cultures.

Correspondence should be addressed to Dr. Futerman at the above address.

Copyright (C) 1997 Society for Neuroscience 0270-6474/97/172929-10\$05.00/0
}

(sphinganine) and sphingosine to dihydroceramide and ceramide, respectively (Merrill et al., 1996), disrupted axon growth during the early part of stage 3, between days 2 and 3 in culture (Harel and Futerman, 1993). Subsequent studies using two other inhibitors of SL metabolism, D-threo-1-phenyl-2-decanoylamino-3morpholino-1-propanol (D-PDMP), which inhibits glucosylation of ceramide to glucosylceramide (GlcCer; Radin and Vunnam, 1981; Inokuchi and Radin, 1987), and conduritol B-epoxide (CBE), which inhibits the lysosomal degradation of GlcCer to ceramide (Legler, 1977), suggested that ongoing synthesis of GlcCer, rather than ceramide, might be required for axonal growth in stage 3 (Schwarz et al., 1995).

The reason that ongoing SL synthesis is required for axon growth is not known, but SLs play important regulatory roles in at least two intracellular processes. First, SLs are involved in regulating intracellular transport via both the exo- and endocytic pathways (Simons and van Meer, 1988; Lisanti and RodriguezBoulan, 1990; Rosenwald et al., 1992; Rosenwald and Pagano, 1993; Chen et al., 1995; Futerman, 1995). In addition, SLs and SL degradation products act as second messengers in signal transduction pathways (Hannun and Bell, 1989), with ceramide participating in growth inhibition, in induction of differentiation, and in programmed cell death (Kolesnick, 1992; Hannun, 1994; Hannun and Obeid, 1995; Hannun et al., 1996).

In the current study we have further analyzed the roles of ceramide and GlcCer at different stages of neuronal development by using various stereoisomers of ceramide in combination with D-PDMP and $\mathrm{FB}_{1}$. Our data indicate that ceramide and GlcCer play distinct roles in the same neuron at different stages of growth, presumably because of their involvement in distinct intracellular events at each developmental stage. 


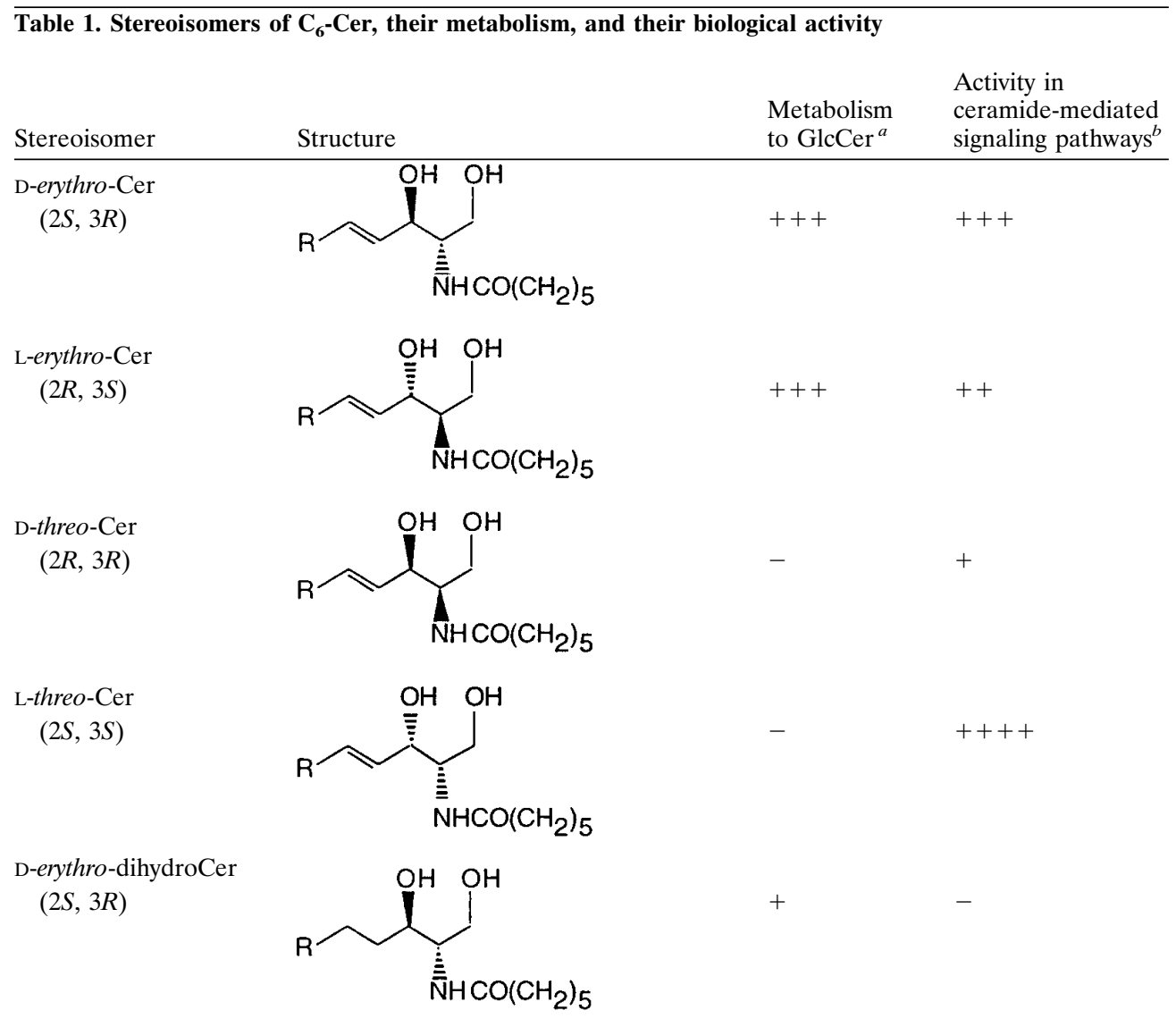

The structures of the four stereoisomers of $\mathrm{C}_{6}$-Cer and the structure of $\mathrm{C}_{6}$-D-erythro-dihydroCer are shown, along with the $R / S$ nomenclature for clarification. The sphingoid long chain base is indicated by $\mathrm{R}$. The extent of metabolism of the stereoisomers to $\mathrm{C}_{6}$-GlcCer and their activities in ceramide-mediated signaling pathways are taken from published data. ${ }^{a}$ Pagano and Martin (1988); Paul et al. (1996).

${ }^{b}$ The activity of the ceramide stereoisomers in signaling pathways was determined for $\mathrm{C}_{2}$-ceramides (Bielawska et al., 1993; Fishbein et al., 1993).

\section{MATERIALS AND METHODS}

Materials. $\mathrm{FB}_{1}$ was obtained from the Division of Food Science and Technology, CSIR (Pretoria, South Africa). D-PDMP, $N$-hexanoyl-Derythro-sphingosine ( $\mathrm{C}_{6}$-D-erythro-Cer), $N$-hexanoyl-D-threo-sphingosine ( $\mathrm{C}_{6}$-D-threo-Cer $), \quad N$-hexanoyl-L-threo-sphingosine $\quad\left(\mathrm{C}_{6}\right.$-L-threo-Cer $)$, $\mathrm{N}$-hexanoyl-D-erythro-dihydrosphingosine $\quad\left(\mathrm{C}_{6}\right.$-D-erythro-dihydroCer $)$, and $N$-\{6-[(7-nitrobenzo-2-oxa-1,3-diazol-4-yl)amino]hexanoyl $\}$-L-threosphingosine $\left(\mathrm{C}_{6}\right.$-NBD-L-threo-Cer) (Table 1) were obtained from Matreya (Pleasant Gap, PA). Neutral sphingomyelinase (N-SMase) (Staphylococcus aureus) was obtained from Sigma (St. Louis, MO). $\mathrm{N}-\{6-$ [(7-nitrobenzo-2-oxa-1,3-diazol-4-yl)amino]hexanoyl\}-D-erythro-sphingosine $\left(\mathrm{C}_{6}\right.$-NBD-D-erythro-Cer) was obtained from Molecular Probes (Eugene, OR). All other chemicals were obtained from Sigma, and solvents (analytical grade) were obtained from Bio-Lab Laboratories (Jerusalem, Israel).

Hippocampal cultures. Hippocampal neurons were cultured at low density as described (Goslin and Banker, 1991) with some modifications (Harel and Futerman, 1993; Schwarz et al., 1995). Briefly, the dissected hippocampi of embryonic day 18 rats (Wistar), obtained from the Weizmann Institute Breeding Center, were dissociated by trypsinization $\left(0.25 \% \mathrm{w} / \mathrm{v}\right.$, for $15 \mathrm{~min}$ at $\left.37^{\circ} \mathrm{C}\right)$. The tissue was washed in $\mathrm{Mg}^{2+} / \mathrm{Ca}^{2+}$. free HBSS (Life Technologies, Gaithersburg, MD) and dissociated by repeated passage through a constricted Pasteur pipette. Cells were plated in minimal essential medium (MEM) with $10 \%$ horse serum at a density of 6000 cells per $13 \mathrm{~mm}$ glass coverslip (Assistent, Germany) that had been precoated with poly-L-lysine $(1 \mathrm{mg} / \mathrm{ml})$. After $3-4 \mathrm{hr}$, coverslips were transferred into 24-well multidishes (Nunc, Roskilde, Denmark) containing a monolayer of astroglia. Coverslips were placed with the neurons facing downward and were separated from the glia by paraffin "feet." Cultures were maintained in serum-free medium (MEM) that included N2 supplements (Goslin and Banker, 1991), ovalbumin $(0.1 \%$, $\mathrm{w} / \mathrm{v})$, and pyruvate $(0.1 \mathrm{~mm})$. In some experiments neurons were removed from multidishes containing glia and placed in new dishes that contained fresh medium but did not contain a glial monolayer.

Neurons cultured at high density (230,000 cells per $24 \mathrm{~mm}$ glass coverslip in $100 \mathrm{~mm}$ Petri dishes) were used for biochemical analysis (Schwarz et al., 1995; Hirschberg et al., 1996).

Analysis of neuronal morphology. Stock solutions of $\mathrm{FB}_{1}$ or D-PDMP were dissolved in HEPES buffer (20 mM, $\mathrm{pH} 7.4)$ and added to cultures to give final concentrations of 50 and $250 \mu \mathrm{M}$, respectively. $\mathrm{C}_{6}$-ceramides were dissolved in ethanol and added to the culture medium so that the final ethanol concentration did not exceed $1 \%$; control cultures were treated with $1 \%$ ethanol. $\mathrm{C}_{6}$-NBD-ceramides were added to cultures either in ethanol or as complexes with defatted bovine serum albumin (BSA; Pagano and Martin, 1994).

For morphological analysis coverslips were removed from the 24-well multidishes, and neurons were fixed in $1 \%(\mathrm{v} / \mathrm{v})$ glutaraldehyde in PBS for $20 \mathrm{~min}$ at $37^{\circ} \mathrm{C}$ and mounted for microscopic examination in $50 \%(\mathrm{w} / \mathrm{v})$ glycerol in PBS. Neurons were examined by phase-contrast microscopy with an Achroplan $32 \times / 0.4$ numerical aperture (NA) phase 2 objective of a Zeiss Axiovert 35 microscope. Neuronal development was analyzed via the developmental criteria of Dotti et al. (1988). The following parameters of neuronal development were measured (Schwarz et al., 1995). (1) The number of cells in stage 1,2 and 3: a cell was considered to be in stage 3 when the major axonal process was $\geq 30 \mu \mathrm{m}$ [i.e., $\sim 10 \mu \mathrm{m}$ longer than the next longest minor process (Goslin and Banker, 1989)]. (2) The length of the total axon plexus, which includes the length of the parent axon and all axonal branches: for 3-d-old neurons, only those cells in which the whole axon plexus could be delineated unambiguously were measured; for 1-d-old neurons, the length of the axon was measured only in cells that had entered stage 3. (3) The number of axonal branch points per cell: an axon was considered to branch when the process to which it 
gave rise was $>15 \mu \mathrm{m}$ long. Thin filopodia, which occasionally were observed along the entire length of the axon, were not considered as branches. In all cases values were pooled from a number of separate cultures, and statistical analysis was performed by the Student's $t$ test.

Analysis of neuronal apoptosis. Neuronal apoptosis was detected with two methods. (1) Chromatin staining of neurons with Hoechst 33342 (bis-benzimide): coverslips containing neurons were washed in HBSS, and neurons were fixed with $4 \%$ formaldehyde for $30 \mathrm{~min}$ at $37^{\circ} \mathrm{C}$ and washed in HBSS for $10 \mathrm{~min}$. Then neurons were incubated with $1 \mu \mathrm{g} / \mathrm{ml}$ Hoechst 33342 stain (Sigma) for $10 \mathrm{~min}$ and washed with HBSS. Cells were observed with a NeoPlan $40 \times / 0.75$ NA objective of a Zeiss Axioskop microscope and an appropriate filter for UV light. (2) Annexin V-binding and propidium iodide labeling: neurons were washed in HBSS and incubated with either fluorescein-conjugated human annexin $\mathrm{V}$ or propidium iodide (Apoptosis detection kit; R \& D Systems, Minneapolis, $\mathrm{MN}$ ) for $10 \mathrm{~min}$ at room temperature; subsequently, neurons were observed with a NeoPlan $63 \times / 1.40$ NA oil objective of a Zeiss Axiovert 35 microscope with appropriate filters for fluorescein and rhodamine (propidium iodide) fluorescence.

Analysis of $C_{6}-N B D$-Cer metabolism. High density cultures (Hirschberg et al., 1996) were incubated with $5 \mu \mathrm{M} \mathrm{C_{6 }}$-NBD-ceramides. After $24 \mathrm{hr}$ cells were removed from the coverslips by scraping with a rubber policeman into distilled water and lyophilized. The dried material was extracted by the procedure of Bligh and Dyer (1959). $\mathrm{C}_{6}$-NBD-SLs were separated by thin-layer chromatography, using $\mathrm{CHCl}_{3} / \mathrm{CH}_{3} \mathrm{OH} / 9.8 \mathrm{~mm} \mathrm{CaCl} 2$ (60: $35: 8, \mathrm{v} / \mathrm{v} / \mathrm{v})$ as the developing solvent, and identified using authentic standards. For quantification of NBD fluorescence, lipids were recovered from the plates by scraping, followed by extraction (Bligh and Dyer, 1959) and NBD fluorescence $\left(\lambda_{\mathrm{ex}}=468 \mathrm{~nm} ; \lambda_{\mathrm{em}}=530 \mathrm{~nm}\right)$ measured with a Perkin-Elmer Instruments LS-5B luminescence spectrometer (Oak Brook, IL).

\section{RESULTS}

\section{GlcCer synthesis is required for axon growth during stage 3}

We previously demonstrated that both $\mathrm{FB}_{1}(10 \mu \mathrm{M})$ and D-PDMP $(50 \mu \mathrm{M})$ disrupt axon growth in hippocampal neurons between days 2 and 3 in culture by affecting the formation or stabilization of collateral axonal branches (Schwarz et al., 1995). Addition of $\mathrm{C}_{6}$-NBD-D-erythro-Cer $(5 \mu \mathrm{M})$ to hippocampal neurons, together with $\mathrm{FB}_{1}(10 \mu \mathrm{M})$, antagonized the disruptive effects of $\mathrm{FB}_{1}$ on axonal growth (Harel and Futerman, 1993); similarly, $\mathrm{C}_{6}$-NBDD-erythro-Cer reversed the inhibitory effect of $\mathrm{FB}_{1}$ on dendritic growth in cultured Purkinje neurons (Furuya et al., 1995). In contrast, we now demonstrate that $\mathrm{C}_{6}$-NBD-D-erythro-Cer was

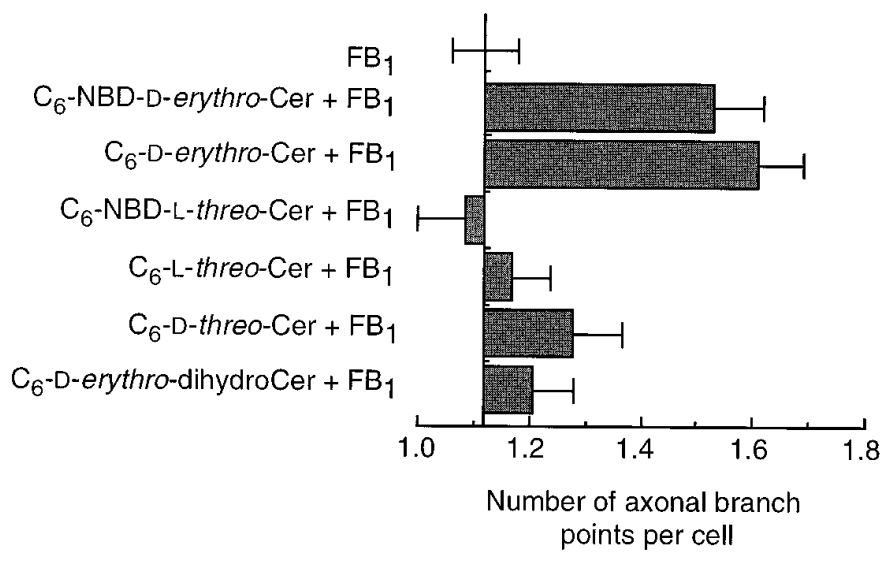

Figure 1. The ability of ceramide stereoisomers to reverse the inhibitory effects of $\mathrm{FB}_{1}$ on axonal growth. Neurons were incubated with $\mathrm{FB}_{1}(50$ $\mu \mathrm{M})$, together with ceramide stereoisomers $(5 \mu \mathrm{M})$ on day 2 , and the number of axonal branch points per cell was measured on day 3 ; the number of axonal branch points in untreated cells on day 3 was $1.67 \pm$ 0.07 . Each error bar is the mean \pm SE of measurements of $200-450$ cells from seven separate cultures.

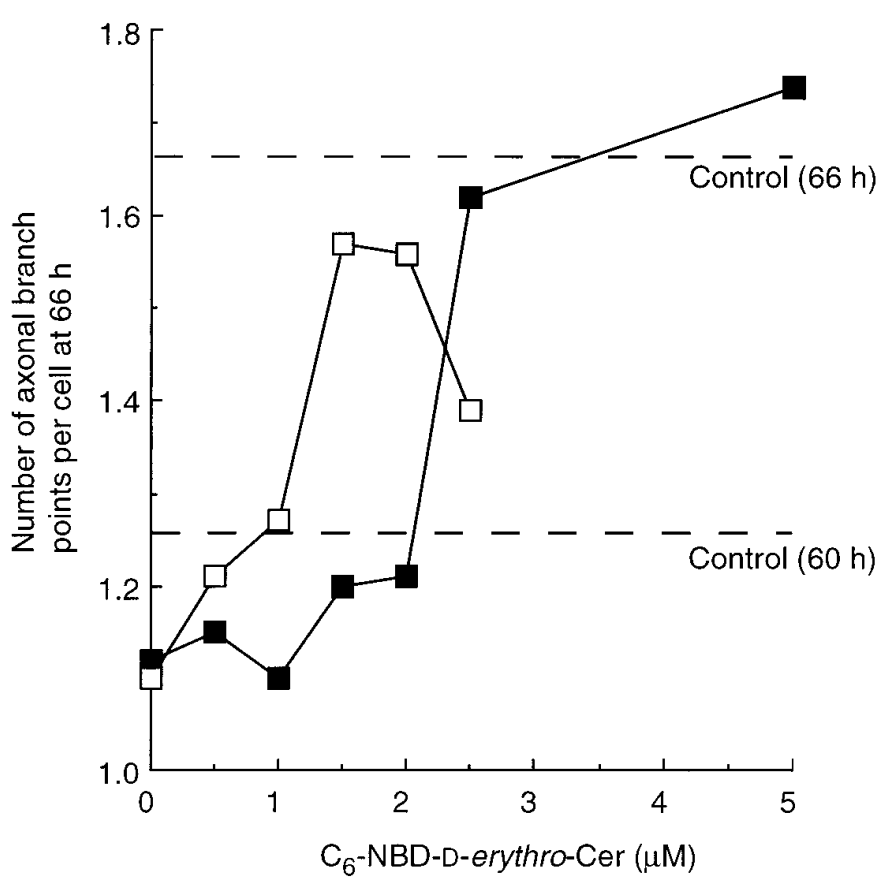

Figure 2. Comparison of the ability of $\mathrm{C}_{6}-\mathrm{NBD}$-D-erythro-Cer to reverse the inhibitory effects of $\mathrm{FB}_{1}$ on neurons growing in the absence or presence of glia. After neurons were cultured for $60 \mathrm{hr}$ in multiwell dishes containing a glial monolayer (see Materials and Methods), coverslips were removed, placed in new multiwell dishes that did not contain a glial monolayer, and incubated with $\mathrm{FB}_{1}(50 \mu \mathrm{M})$ together with increasing concentrations of $\mathrm{C}_{6}$-NBD-D-erythro-Cer. The number of axonal branch points was measured at $66 \mathrm{hr}$ for neurons grown between 60 and $66 \mathrm{hr}$ without glia $(\square)$ and compared with neurons grown between 60 and $66 \mathrm{hr}$ with glia $(\boldsymbol{\square})$. The dashed lines show the number of branch points in untreated control cells at 60 and $66 \mathrm{hr}$. Each point is the mean of measurements of 100-150 cells from two separate cultures; the SE for each point varied between 0.09 and 0.15 .

completely ineffective in reversing the effects of D-PDMP on axonal growth in hippocampal neurons; the number of axonal branch points per cell was $1.7 \pm 0.2$ on day 3 in untreated cells, but in cells treated on day 2 with either D-PDMP $(250 \mu \mathrm{M})$ or D-PDMP $(250 \mu \mathrm{M})$, together with $\mathrm{C}_{6}$-NBD-D-erythro-Cer $(5 \mu \mathrm{M})$,

Table 2. The effects of $\mathrm{C}_{6}$-NBD-D-erythro-Cer, $\mathrm{FB}_{1}$, and D-PDMP on neuronal development between day 0 and 1 in culture

\begin{tabular}{ll} 
Treatment & $\begin{array}{l}\text { Length of axon } \\
\text { plexus }(\mu \mathrm{m}) \text { on day } 1\end{array}$ \\
\hline Control & $126 \pm 3$ \\
$\mathrm{C}_{6}$-NBD-D-erythro-Cer $(5 \mu \mathrm{M})$ & $183 \pm 5$ \\
$\mathrm{FB}_{1}(50 \mu \mathrm{M})$ & $127 \pm 4^{a}$ \\
$\mathrm{FB}_{1}(50 \mu \mathrm{M})+\mathrm{C}_{6}$-NBD-D-erythro-Cer $(5 \mu \mathrm{M})$ & $188 \pm 10$ \\
D-PDMP $(250 \mu \mathrm{M})$ & $127 \pm 4$ \\
D-PDMP $(250 \mu \mathrm{M})+\mathrm{C}_{6}$-NBD-D-erythro-Cer & \\
$\quad(5 \mu \mathrm{M})$ & $183 \pm 6$ \\
\hline
\end{tabular}

Compounds were added immediately after cells were placed in multiwell dishes containing cocultures of glial cells, and the length of the axon plexus was measured at $24 \mathrm{hr}$. Each number represents the mean $\pm \mathrm{SE}$ of measurements from two separate cultures in which $\sim 50$ cells per coverslip were counted on two individual coverslips per treatment.

${ }^{a}$ We assume that $\mathrm{FB}_{1}$ has no effect on neuronal development between days 0 and 1 because there is a sufficiently large pool of sphingomyelin to generate all the endogenous ceramide that is required for the transition from stage 1 to 2 ; a similar suggestion about endogenous sphingomyelin pools was made by Wiesner and Dawson (1996). 


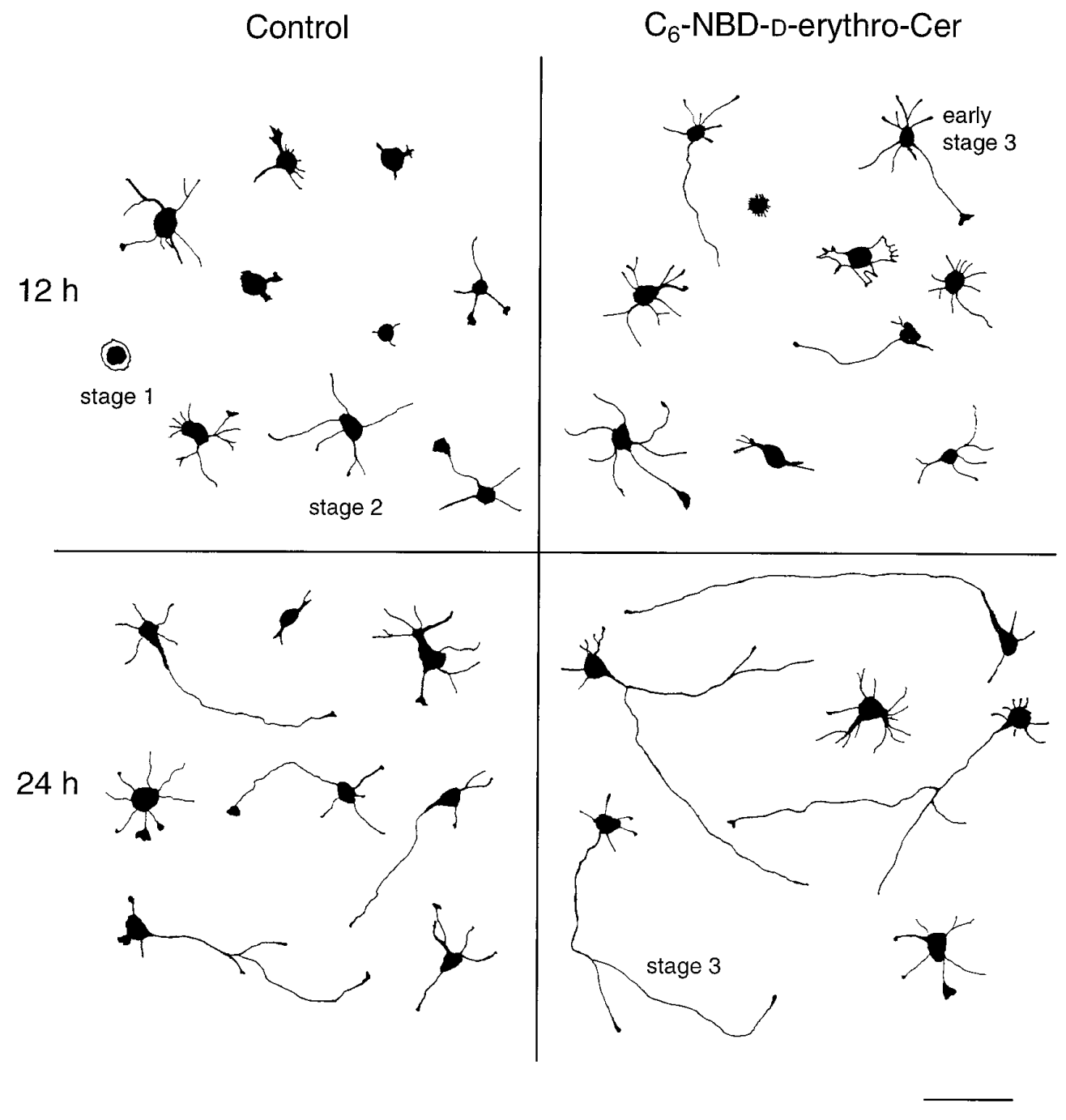

Figure 3. Morphological characteristics of hippocampal neurons. Shown are camera lucida drawings of representative cells at 12 and $24 \mathrm{hr}$ in culture after addition of $\mathrm{C}_{6}$-NBD-D-erythro-Cer immediately after cells were placed in multiwell dishes. The developmental stages of some cells are indicated. Scale bar, $50 \mu \mathrm{m}$. the number of axonal branch points per cell on day 3 was $1.0 \pm 0.1$ and $1.1 \pm 0.1$, respectively. These data are consistent with the suggestion (Schwarz et al., 1995) that $\mathrm{C}_{6}$-NBD-D-erythro-Cer must be metabolized to $\mathrm{C}_{6}$-NBD-D-erythro-GlcCer to support axonal growth during stage 3 .

To corroborate this suggestion and to exclude the possibility that the ability of $\mathrm{C}_{6}$-NBD-D-erythro-Cer to reverse the effects of $\mathrm{FB}_{1}$ is attributable to a ceramide-mediated signaling pathway (Hannun et al., 1996), we tested the ability of various stereoisomers of ceramide to reverse the inhibitory effects of $\mathrm{FB}_{1}$ on axonal growth. Naturally occurring ceramide occurs in the D-erythro- configuration, but three other stereoisomers exist, some of which are metabolized to GlcCer and some of which are active in ceramide-mediated signaling pathways (Table 1). For instance, exogenously added L-threo-Cer is not metabolized to L-threo-GlcCer in cultured cells (Pagano and Martin, 1988) or by purified GlcCer synthase (Paul et al., 1996), but it does activate intracellular signaling pathways (Bielawska et al., 1993; Fishbein et al., 1993).

Only the D-erythro forms of ceramide $\left(\mathrm{C}_{6}-\mathrm{NBD}\right.$-D-erythro-Cer and $\mathrm{C}_{6}$-D-erythro-Cer) were able to reverse the disruptive effects of $\mathrm{FB}_{1}$ on axonal growth between days 2 and 3 , but $\mathrm{C}_{6}$-NBD-L-threoCer and $\mathrm{C}_{6}$-L-threo-Cer were essentially ineffective, as were $\mathrm{C}_{6}$-Derythro-dihydroCer and $\mathrm{C}_{6}$-D-threo-Cer (Fig. 1). During this period $42 \pm 4 \%$ of $\mathrm{C}_{6}$-NBD-D-erythro-Cer was metabolized to $\mathrm{C}_{6}$ -
NBD-D-erythro-GlcCer, but $<1 \%$ of $\mathrm{C}_{6}$-NBD-L-threo-Cer was metabolized to $\mathrm{C}_{6}$-NBD-L-threo-GlcCer. None of the stereoisomers was able to reverse the inhibitory effects of D-PDMP on neuronal growth. Because $\mathrm{C}_{6}-\mathrm{NBD}-\mathrm{D}$-erythro-Cer is metabolized in hippocampal neurons only to $\mathrm{C}_{6}$-NBD-D-erythro-GlcCer and not to higher order $\mathrm{C}_{6}$-NBD-D-erythro-glycolipids (i.e., $\mathrm{C}_{6}$-NBDD-erythro-gangliosides; although small amounts of $\mathrm{C}_{6}-\mathrm{NBD}-\mathrm{D}-$ erythro-lactosylceramide are formed, $<2.5 \%$ of the total recovered NBD fluorescence) or to $\mathrm{C}_{6}$-NBD-D-erythro-sphingomyelin (Harel and Futerman, 1993), it seems that GlcCer itself is able to sustain axonal growth between days 2 and 3 without the need for metabolism to higher order glyco-SLs or to sphingomyelin.

To determine whether the glial cells present in the multiwell dishes (see Materials and Methods) might be contributing to the ability of $\mathrm{FB}_{1}$ to disrupt neuronal growth and of $\mathrm{C}_{6}$-NBD-Derythro-Cer to antagonize the effects of $\mathrm{FB}_{1}$, parallel experiments were performed on neurons cultured between 60-66 hr (Schwarz et al., 1995) in multiwell dishes containing fresh medium but not containing a glial monolayer. $\mathrm{FB}_{1}$ inhibited neuronal growth in the absence of glia to a similar extent to that observed in the presence of glia (Fig. 2), and $\mathrm{C}_{6}-\mathrm{NBD}$-D-erythro-Cer reversed the inhibitory effects of $\mathrm{FB}_{1}$, although at a lower concentration than those effective in the presence of glia (Fig. 2). Moreover, $5 \mu \mathrm{M}$ $\mathrm{C}_{6}$-NBD-D-erythro-Cer caused apoptotic cell death in neurons 

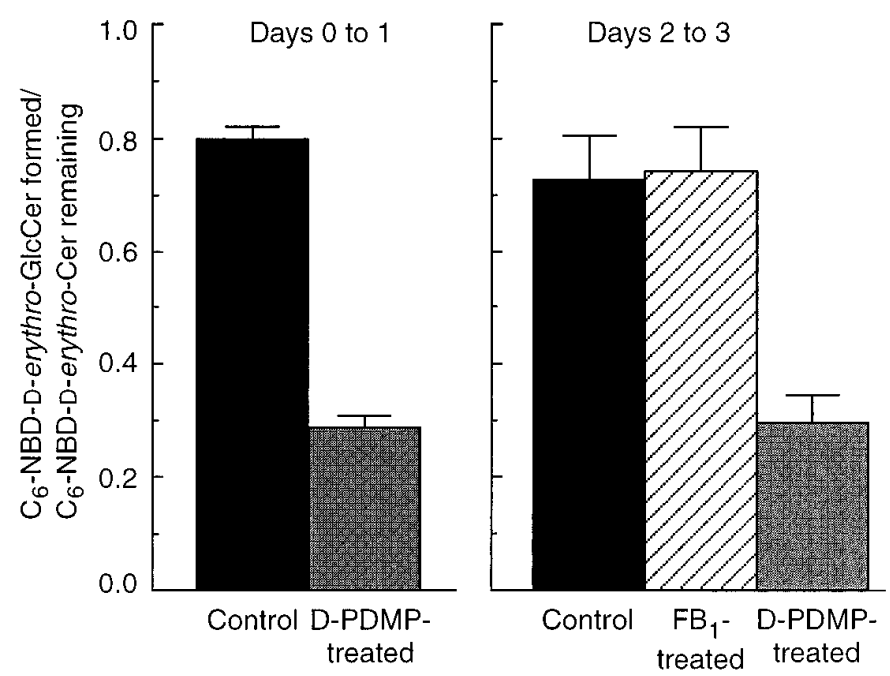

Figure 4. The metabolism of $\mathrm{C}_{6}$-NBD-D-erythro-Cer. Neurons were incubated with $\mathrm{C}_{6}$-NBD-D-erythro-Cer $(5 \mu \mathrm{M})$ added as an equimolar complex with BSA, in the absence or presence of $\mathrm{FB}_{1}(50 \mu \mathrm{M})$ or D-PDMP $(250 \mu \mathrm{M}$, from days 0 to 1 or from days 2 to 3 . The metabolism of $\mathrm{C}_{6}$-NBD-D-erythro-Cer is expressed as a ratio of the amount of $\mathrm{C}_{6}$-NBDD-erythro-GlcCer formed $/ \mathrm{C}_{6}$-NBD-D-erythro-Cer remaining. Each error bar represents the mean of two (days 0-1) or three (days 2-3) experiments.

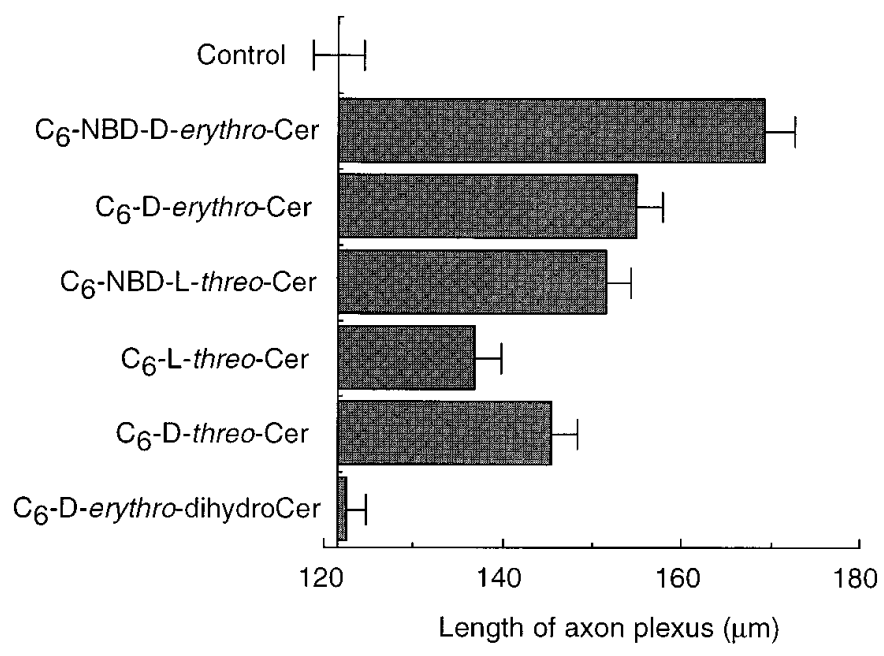

Figure 5. The effects of ceramide stereoisomers on neuronal development on days $0-1$. Neurons were incubated on day 0 with ceramide stereoisomers $(5 \mu \mathrm{M})$ added from a stock solution in ethanol, and axon lengths were measured on day 1 for stage 3 cells. Each error bar is the mean \pm SE of measurements of $400-500$ cells from five separate cultures.

grown in the absence of glia (see below), although it had no effect on cell viability of neurons grown with glia, where it antagonized the disruptive effects of $\mathrm{FB}_{1}$ on axonal growth (Figs. 1, 2).

\section{Ceramide stimulates the transition of neurons from stage 1 to 2}

In contrast to their inhibitory effects on axonal growth between days 2 and 3, neither $\mathrm{FB}_{1}$ nor D-PDMP had any effect on axonal growth during the first $24 \mathrm{hr}$ in culture (Table 2), even at fivefold higher concentrations than previously used (Schwarz et al., 1995). However, incubation with $\mathrm{C}_{6}$-NBD-D-erythro-Cer caused a $40-$ $50 \%$ increase in the length of the axon plexus during the initial 24 $\mathrm{hr}$ in culture (Table 2) and an increase in the number of cells in stage 3 after 24 hr (Fig. 3).

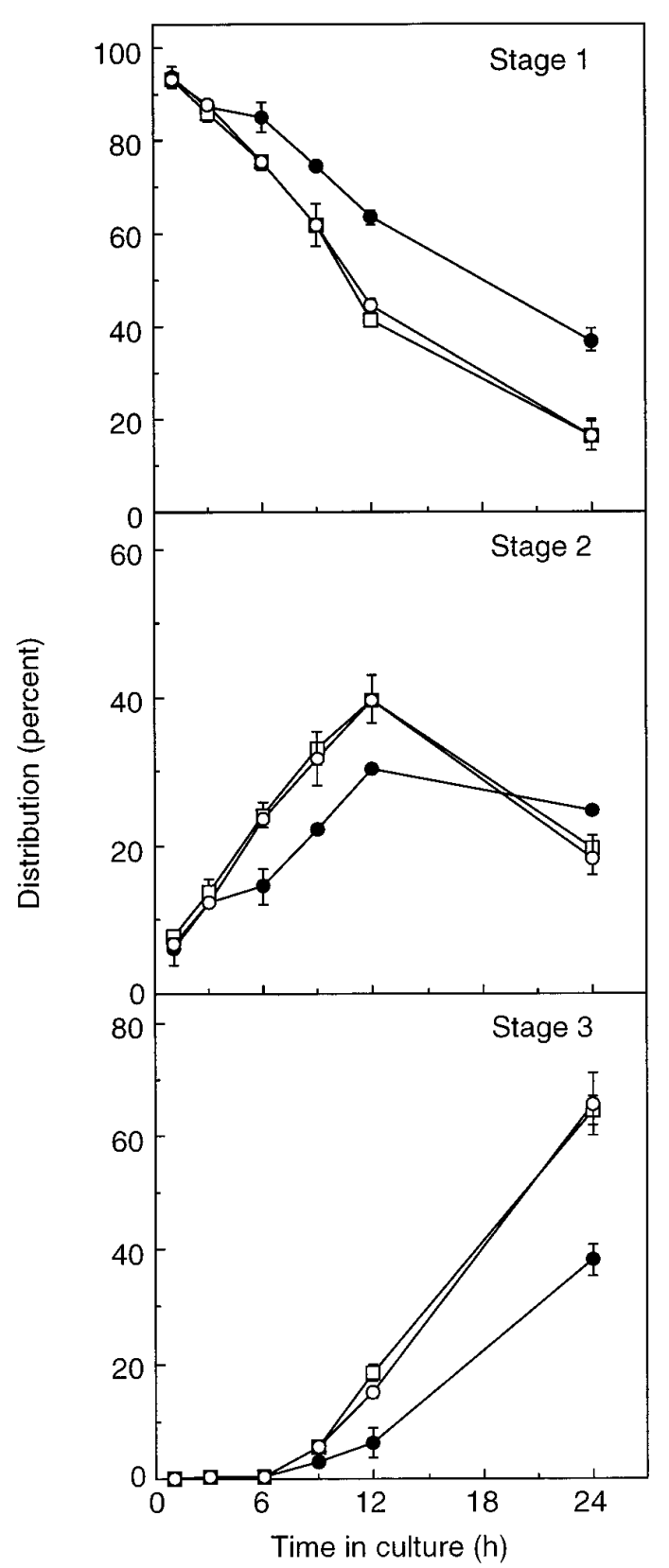

Figure 6. The effect of $\mathrm{C}_{6}$-NBD-D-erythro-Cer on the transition of neurons from stage 1 through 3. Neurons were incubated with $\mathrm{C}_{6}-\mathrm{NBD}-\mathrm{D}-$ erythro-Cer $(\mathrm{O})$ or $\mathrm{C}_{6}$-NBD-D-erythro-ceramide, together with D-PDMP $(\square)$, and the number of cells at each developmental stage was compared with untreated cells $(\bullet)$. Each point represents the mean \pm SE of measurements from two separate cultures in which 100 cells per coverslip were analyzed for two individual coverslips per treatment.

Neither D-PDMP nor $\mathrm{FB}_{1}$ could block the stimulatory effects of $\mathrm{C}_{6}$-NBD-D-erythro-Cer (Table 2), demonstrating that $\mathrm{C}_{6}$-NBD-Derythro-Cer stimulates axonal growth during early stages of development independent of its metabolism to $\mathrm{C}_{6}$-NBD-D-erythroGlcCer. The inability of D-PDMP to block the stimulatory effects of $\mathrm{C}_{6}$-NBD-D-erythro-Cer on axonal growth during the first day in culture was not attributable to altered efficacy of the inhibitor at different stages of development, because incubation with D-PDMP inhibited the metabolism of $\mathrm{C}_{6}-\mathrm{NBD}$-D-erythro-Cer to $\mathrm{C}_{6}-\mathrm{NBD}$ D-erythro-GlcCer to a similar extent between days $0-1$ and 2-3 (Fig. 4). 
Table 3. The transition of hippocampal neurons from stages 1 through 3

\begin{tabular}{llll} 
& \multicolumn{1}{l}{$t_{1 / 2}(\mathrm{hr})$} & & \\
\cline { 2 - 4 } Treatment & Stage 1 & Stage 2 & Stage 3 \\
\hline Control & 18.6 & $21.9(1.17)$ & $30.0(1.37)$ \\
C $_{6}$-NBD-D-erythro-Cer & 13.0 & $15.1(1.16)$ & $20.3(1.34)$ \\
C $_{6}$-NBD-D-erythro-Cer + & & & \\
$\quad$ D-PDMP & 12.8 & $15.1(1.18)$ & $20.3(1.35)$
\end{tabular}

Data are taken from Figure 6. $t_{1 / 2}$ was calculated for each stage from a slope obtained by linear regression analysis; in all cases, $r^{2}$ was between 0.96 and $0.99 . t_{1 / 2}$ stage 1 is the average time that $50 \%$ of the cells remain in this stage before entering stage 2 . $t_{1 / 2}$ stage 2 is the average time that it would take for $50 \%$ of the cells to accumulate in this stage. However, because stage 2 is an intermediate stage before transition to stage 3 , this value is never reached; the slope for stage 2 therefore was obtained using data from the first $12 \mathrm{hr}$ only. $t_{1 / 2}$ stage 3 is the average time taken for $50 \%$ of the cells to enter this stage; note that because there were essentially no cells in stage 3 for the first $6 \mathrm{hr}$, the slope was obtained using data from 6 to $24 \mathrm{hr}$. The numbers in parentheses in the column labeled stage 2 are the ratios $t_{1 / 2}$ stage $2 / t_{1 / 2}$ stage 1 , and the numbers in parentheses under stage 3 are the ratios $t_{1 / 2}$ stage $3 / t_{1 / 2}$ stage 2 .

The effects of ceramide stereoisomers on axon growth during the first $24 \mathrm{hr}$ in culture were consistent with the notion that ceramide mediates its effects at this stage of development via a signaling pathway and not via a process that depends on metabolism to GlcCer. Both $\mathrm{C}_{6}-\mathrm{NBD}-\mathrm{D}$-erythro-Cer and $\mathrm{C}_{6}-\mathrm{NBD}-\mathrm{L}-$ threo-Cer stimulated growth between days 0 and 1 (Fig. 5), as did their nonfluorescent, short-acyl chain counterparts (Fig. 5), albeit to a smaller extent. However, whereas $45 \pm 1 \%$ of $\mathrm{C}_{6}$-NBD-Derythro-Cer was metabolized to $\mathrm{C}_{6}$-NBD-D-erythro-GlcCer during a $24 \mathrm{hr}$ incubation from day 0 to 1 , only $1 \%$ of $\mathrm{C}_{6}$-NBD-L-threoCer was metabolized to $\mathrm{C}_{6}$-NBD-L-threo-GlcCer. $\mathrm{C}_{6}$-D-threo-Cer also stimulated growth (Fig. 5), but $\mathrm{C}_{6}$-D-erythro-dihydroCer, which is totally inactive in signaling pathways (Table 1 ), had no effect (Fig. 5).

The increased axon lengths observed after incubation with ceramide for the first $24 \mathrm{hr}$ in culture could be explained by two possibilities. Ceramide could accelerate the rate of transition from one developmental stage to another; or alternatively, it could have no effect on the rate of transition but, rather, could accelerate the rate of axon growth once cells have entered stage 3 .

Analysis of the number of neurons in each developmental stage during the first $24 \mathrm{hr}$ in culture demonstrated that minor process formation, i.e., the transition from stage 1 to 2 , was accelerated by treatment with $\mathrm{C}_{6}$-NBD-D-erythro-Cer and that this effect was not blocked by D-PDMP (Fig. 6). The average time that $50 \%$ of control cells remained in stage 1 before entering stage 2 $\left(t_{1 / 2 \text { stage } 1}\right)$ was $18.6 \mathrm{hr}$, whereas the $t_{1 / 2}$ stage 1 for $\mathrm{C}_{6}-\mathrm{NBD}$-Derythro-Cer-treated cells was $13 \mathrm{hr}$ (Table 3). However, the ratio of $t_{1 / 2 \text { stage } 2 / t_{1 / 2} \text { stage } 1}$ and of $t_{1 / 2 \text { stage } 3} / t_{1 / 2}$ stage 2 was identical for both control and treated cells (Table 3 ). This demonstrates that the number of cells in stage 3 is related directly to their rate of transition from stage 1 to 2 and not to differences in the time they spend in stage 2 or differences in their rate of transition from stage 2 to 3. Therefore, the increased axon lengths observed after incubation with $\mathrm{C}_{6}$-NBD-D-erythro-Cer for the first $24 \mathrm{hr}$ in culture are a result of their faster rate of exit from stage 1 and the corresponding increase in the amount of time they spend in stage 3 before measurement, and not the result of an increase in the rate of axon growth once the cells enter stage 3 .

$\mathrm{C}_{6}$-NBD-D-erythro-Cer also stimulated the transition from stage 1 to 2 when cells were cultured in the absence of glia, but at much lower concentrations than in the presence of glia; incubation with $5 \mu \mathrm{M} \mathrm{C}_{6}$-NBD-D-erythro-Cer resulted in a 50-60\% increase in the number of stage 3 cells at $24 \mathrm{hr}$ in the presence of glia (Fig. 6), but in the absence of glia a similar increase in the number of stage 3

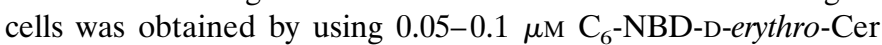
(data not shown). The concentration differences required to see an effect were not attributable to the uptake of $\mathrm{C}_{6}$-NBD-D-erythroCer into glia when neurons were cultured with a glial monolayer and, thus, a reduction in the effective concentration of $\mathrm{C}_{6}-\mathrm{NBD}$ D-erythro-Cer in the medium, because similar amounts of NBD
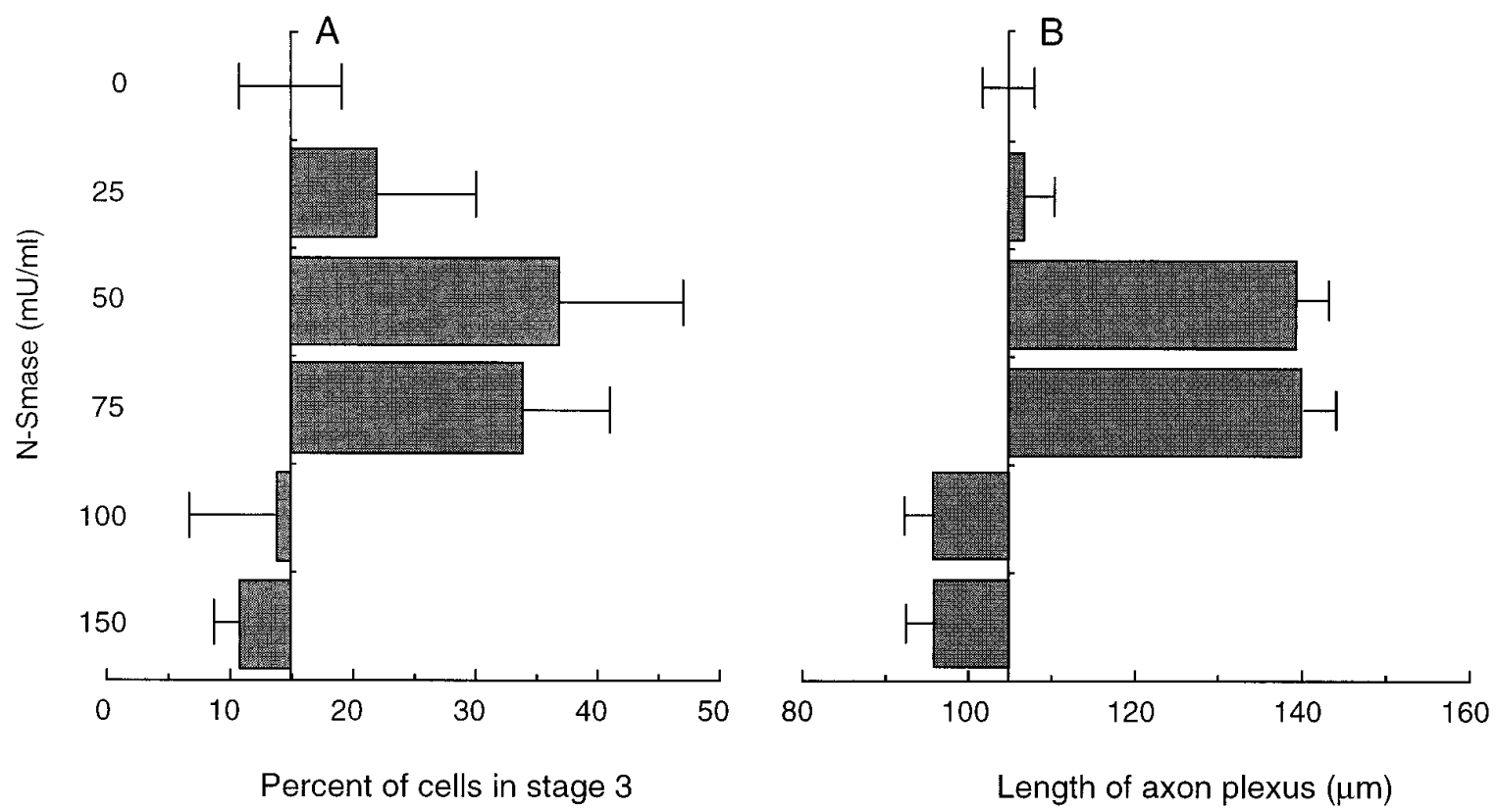

Figure 7. The effect of N-SMase on neuronal development. Neurons cultured in the absence of glia were incubated with various concentrations of $\mathrm{N}$-SMase on day 0 . After $24 \mathrm{hr}$, the percentage of cells in stage $3(A)$ or the length of the axon plexus in stage 3 cells $(B)$ was analyzed. Each error bar is the mean $\pm \mathrm{SE}$ of measurements of $\sim 500$ cells from three separate cultures. 

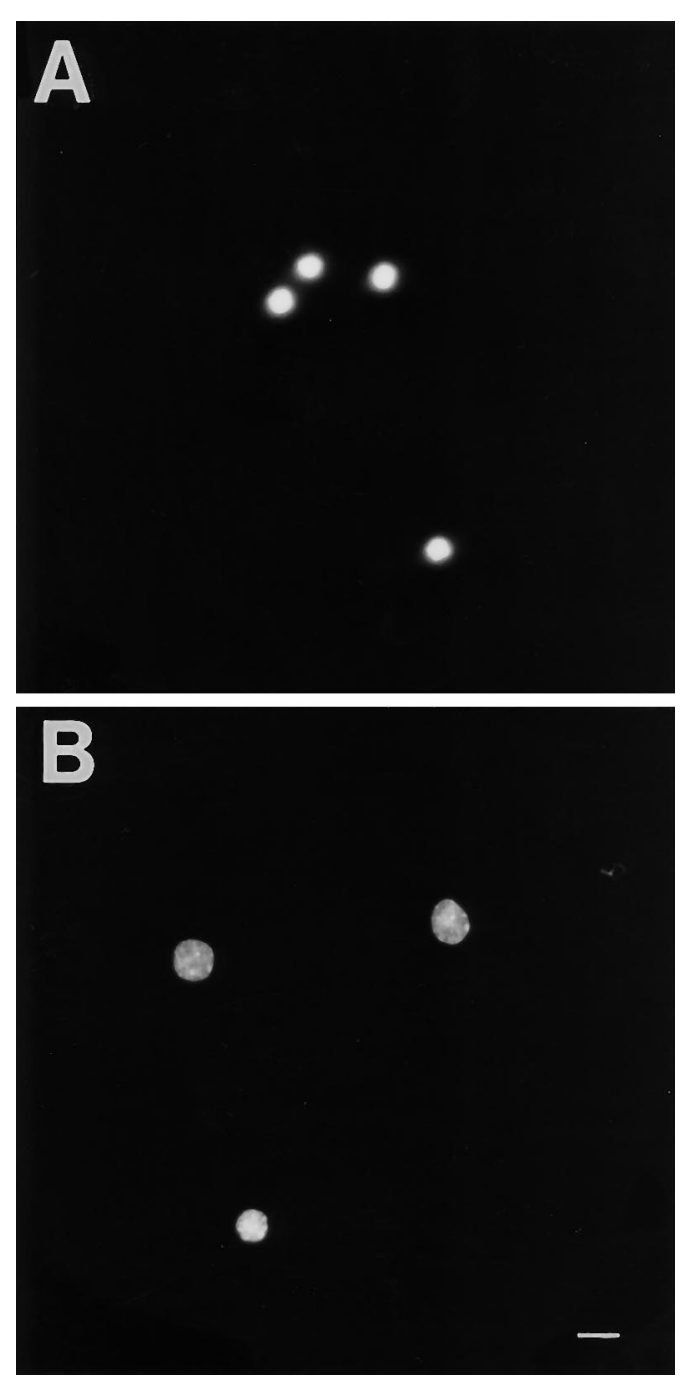

Figure 8. Chromatin condensation in neurons treated with ceramides. Neurons cultured in the absence of glia were incubated with $5 \mu \mathrm{M}$ $\mathrm{C}_{6}$-NBD-D-erythro-Cer $(A)$ or $5 \mu \mathrm{M} \mathrm{C}_{6}$-D-erythro-dihydroCer $(B)$ at 60 $\mathrm{hr}$ in culture and examined for chromatin condensation at $66 \mathrm{hr}$. Scale bar, $10 \mu \mathrm{m}$.

fluorescence were recovered from the culture medium of neurons grown with or without glia. Similar to observations during days 2-3, incubation with $5 \mu \mathrm{M} \mathrm{C}_{6}$-NBD-D-erythro-Cer caused cell death in neurons grown in the absence of glia between days $0-1$ (see below).

To determine whether endogenous ceramide also could stimulate neuronal development, we incubated neurons cultured in the absence of glia with $\mathrm{N}-\mathrm{SMase}$. Incubation with $50-75 \mathrm{mU} / \mathrm{ml}$ resulted in an increase in the percentage of neurons in stage 3 after $24 \mathrm{hr}$ (Fig. 7A) and in an increase in the length of the axon plexus (Fig. 7B). At higher concentrations $(>250 \mathrm{mU} / \mathrm{ml})$ $\mathrm{N}$-SMase induced cell death and hence a reduction in the number of cells in stage 3 .

\section{High concentrations of ceramide induce apoptosis}

Many previous studies have demonstrated that generation of ceramide by incubation with N-SMase, or addition of short-acyl chain analogs of ceramide, induces apoptotic cell death (Hannun and Obeid, 1995). In hippocampal neurons neither $\mathrm{C}_{6}$-NBD-Derythro-Cer nor N-SMase affected cell viability at low concentra- tions (see above), but at higher concentrations, both induced cell death at early (days 0-1) and at later (days 2-3) stages of development. Thus, when 2- to 3-d-old neurons were incubated with 5 $\mu \mathrm{M} \mathrm{C}_{6}$-NBD-D-erythro-Cer or $\mathrm{C}_{6}$-D-erythro-Cer for $6 \mathrm{hr}$ in the absence of glia, chromatin condensation was observed (Fig. 8A) and plasma membrane asymmetry was disrupted, as detected by annexin V-binding (Kroemer et al., 1995) (Fig. 9A,B). Similarly, 5 $\mu \mathrm{M} \mathrm{C}_{6}$-L-threo-Cer induced apoptosis, as did $>250 \mathrm{mU} / \mathrm{ml}$ $\mathrm{N}$-Smase. However, in the presence of glia, $5 \mu \mathrm{M} \mathrm{C}$-NBD-Derythro-Cer had no effect on cell viability (Fig. $9 C, D$ ), but concentrations of $15 \mu \mathrm{M}$ and above did induce apoptosis. When 0 - to 1-d-old neurons were incubated with $\mathrm{C}_{6}$-NBD-D-erythro-Cer, $\mathrm{C}_{6}$ D-erythro-Cer, or $\mathrm{C}_{6}$-L-threo-Cer, cell death was observed at $24 \mathrm{hr}$; for neurons incubated with glia, concentrations of $>15 \mu \mathrm{M} \mathrm{C}_{6}$ NBD-D-erythro-Cer affected cell viability, and in the absence of glia, concentrations of $\sim 1-3 \mu \mathrm{M}$ caused apoptosis. In contrast, incubation with $5 \mu \mathrm{M} \mathrm{C}_{6}$-D-erythro-dihydroCer on day 0 or on days 2-3 had no effect either on chromatin condensation (Fig. $8 B$ ) or on membrane asymmetry (data not shown) in neurons grown without glia. Finally, we confirmed that cell death was attributable to apoptosis and not to necrosis, because cells were not labeled by propidium iodide, a vital stain for necrosis (Kroemer et al., 1995).

\section{DISCUSSION}

In the present study we demonstrate that SLs play three distinct roles in regulating neuronal development (Fig. 10), namely that (1) ceramide enhances the formation of minor processes from lamellipodia, that (2) GlcCer synthesis is required for normal axon growth during stage 3 , and that (3) at both of these stages ceramide can induce apoptotic cell death at high concentrations.

\section{A signaling role for ceramide in minor process formation and in apoptosis}

The lack of specificity of ceramide stereoisomers in regulating the transition from stage 1 to 2 and in inducing apoptosis, together with the lack of effect of dihydroceramide (Bielawska et al., 1993), is consistent with the possibility that ceramide acts via an intracellular signaling pathway in the regulation of these events. Moreover, the decision of whether to enter either of these diametrically opposed pathways seems to depend on ceramide concentration.

In proliferating cells, ceramide suppresses growth and stimulates differentiation (Pushkareva et al., 1995). For instance, ceramide inhibits proliferation of neuroblastoma Neuro2a cells and induces their differentiation (Riboni et al., 1995) and stimulates T9 glioma differentiation and processes formation (Dobrowsky et al., 1994). However, ceramide cannot act via arrest of proliferation and stimulation of differentiation in hippocampal neurons, because these neurons are postmitotic at their time of removal from the hippocampus (Fletcher and Banker, 1989). Rather, ceramide acts by accelerating the transition from stage 1 to 2 (Fig. 10).

During this transition there are major changes in the organization of the actin- and microtubule-based cytoskeletons. After neurons attach to poly-L-lysine-coated coverslips, motile lamellipodia develop around the cell periphery (stage 1; Dotti et al., 1988) that resemble the regions of the ruffling membrane associated with migrating cells. Lamellipodia contain a predominance of actin filaments, mainly concentrated in the radial regions (Goslin et al., 1989), and unoriented microtubules (Dotti et al., 1988). During minor process formation (stage 2) the lamellipodia break up into discrete, motile patches at intervals along the cell periphery, and neurites arise preferentially at these sites (Dotti et al., 1988; Deitch and Banker, 1993). Minor processes form from 

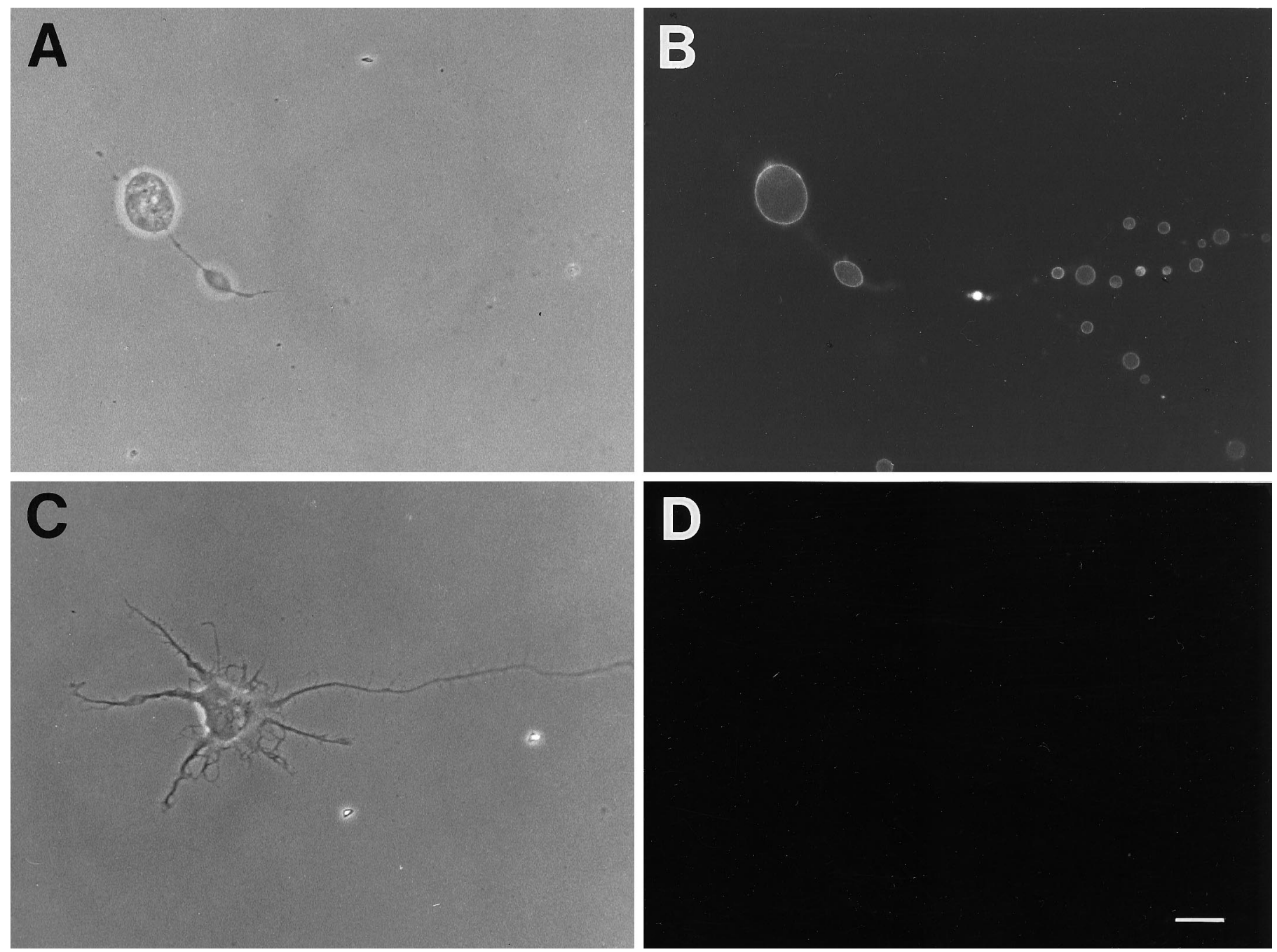

Figure 9. Annexin V-binding to neurons treated with $\mathrm{C}_{6}$-D-erythro-Cer. Neurons cultured in either the absence $(A, B)$ or presence of glia $(C, D)$ were incubated with $5 \mu \mathrm{M} \mathrm{C}_{6}$-D-erythro-Cer at $60 \mathrm{hr}$ in culture. Annexin V-binding was examined between 63 and $64 \mathrm{hr}$. The left panels are phase-contrast micrographs, and the right panels are fluorescence micrographs. Scale bar, $10 \mu \mathrm{m}$.

lamellipodia via an intermediate stage of "wide minor processes," in which microtubules are aligned along the plasma membrane but exhibit a more random orientation within the center of the processes (Deitch and Banker, 1993). These wide minor processes become narrower over time, eventually forming minor processes with highly aligned microtubules and with polymerized actin concentrated in growth cones (Goslin et al., 1989).

We do not know the molecular mechanisms by which ceramide accelerates changes in the cytoskeleton. However, both sphingosine and ceramide stimulate actin stress fiber formation and focal adhesion assembly in Swiss 3 T3 cells as a result of tyrosine phosphorylation of $125^{\mathrm{FAK}}$ and paxillin (Seufferlein and Rozengurt, 1994), which are early events in the action of diverse signaling pathways that lead to alterations in cytoskeletal organization.

In addition to its role in suppressing growth and inducing differentiation, ceramide also induces apoptosis in differentiating cells (Hannun and Obeid, 1995). In hippocampal neurons ceramide also induces apoptosis, although at higher concentrations than those that induce the transition from stage 1 to 2 . Interestingly, neurons grown in the absence of the feeder glial monolayer are far more sensitive to ceramide than neurons grown with glia. It is known that glia play an important role in sustaining neuronal growth and survival (Oppenheim, 1991; Raff et al., 1993), either by absorbing toxic substances secreted from neurons or alternatively by the provision of secreted trophic factors required for neuronal survival. Trophic factor deprivation induces apoptosis in neurons (Dugan et al., 1995), and our data suggest that neuronal death can be accelerated by ceramide upon deprivation of trophic factors.

\section{A role for GlcCer in axon growth}

During the transition from stage 1 to 2, SL synthesis can be blocked completely with no obvious effects on neuronal development. This implies that there is a sufficiently large intracellular pool of SLs at this stage to sustain growth and development. In contrast, during stage 3 ongoing GlcCer synthesis is required for normal growth (Fig. 10); we also recently have shown that ongoing GlcCer synthesis is required for basic fibroblast growth factor and laminin to stimulate axonal growth in hippocampal neurons (Boldin and Futerman, 1997). Similarly, phosphatidylcholine (PC) synthesis is required for the growth of sympathetic neurons (de Chaves et al., 1995). PC comprises $\sim 40-50 \%$ of total neuronal membrane lipids (Siegel et al., 1994), whereas SLs comprise between $15-20 \%$. This might imply that inhibitors of PC synthesis 
Day 0 to 1 in culture

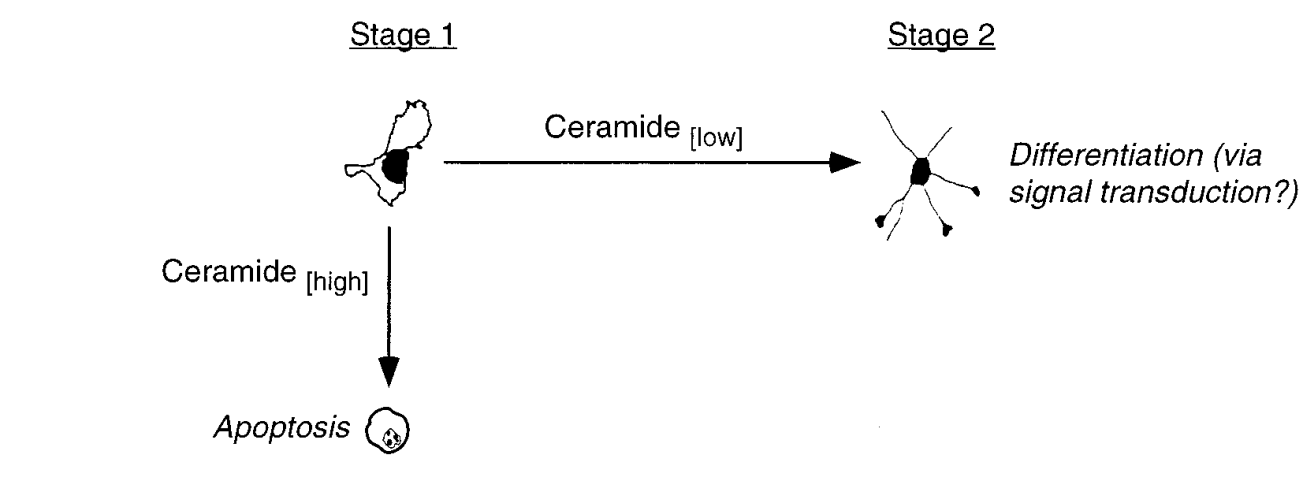

Day 3 in culture (stage 3)

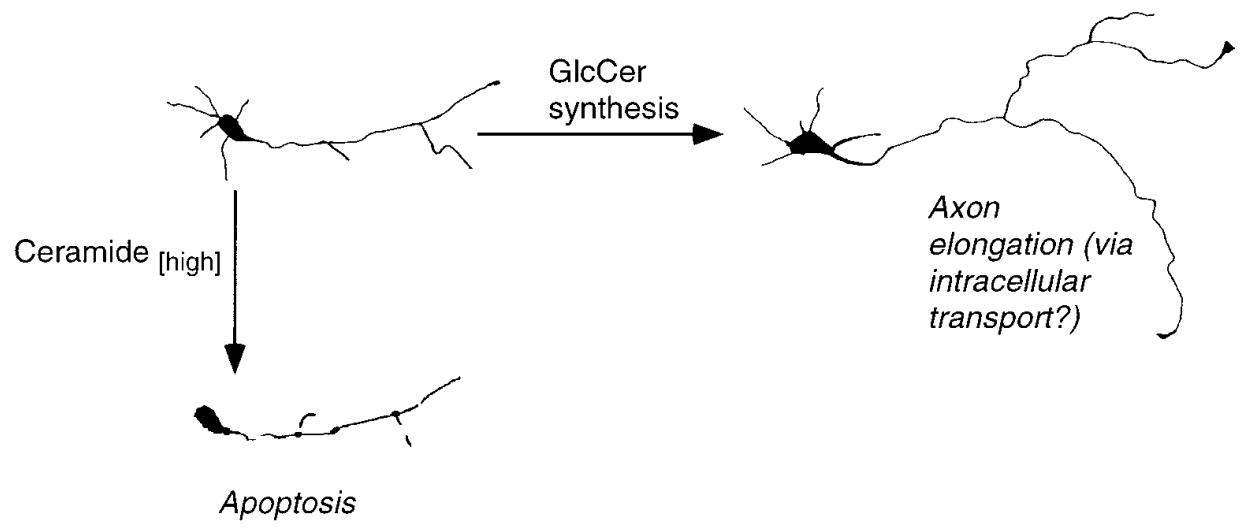

Figure 10. Demonstrated are the roles of ceramide and GlcCer at different stages of neuronal development. See Discussion for further details. act by blocking the delivery to the membrane of "bulk" membrane material that plays a structural role (discussed in Futerman and Banker, 1996). In contrast, inhibitors of SL synthesis might act by disrupting one or other regulatory roles in which SLs are involved. One interesting possibility is that ongoing GlcCer synthesis is required for intracellular protein transport. In this regard it has been proposed that GlcCer and other glyco-SLs are transported preferentially to the axonal membrane (Dotti et al., 1991). Although there is no direct evidence for the preferential sorting of GlcCer and glyco-SLs to axons (for review, see Schwarz and Futerman, 1996), it may be more than a coincidence that the requirement for ongoing GlcCer synthesis arises before the time that the polarized distribution of axonal membrane proteins is first observed (Dotti and Simons, 1990; Fletcher et al., 1991). Ongoing GlcCer synthesis could be required for the delivery to the axonal membrane of a protein that is essential for axon growth. In Chinese hamster ovary cells inhibition of GlcCer synthesis blocks the delivery of a viral protein to the cell surface (Rosenwald et al., 1992), although these effects subsequently have been attributed to the accumulation of ceramide [Rosenwald and Pagano (1993); see also Chen et al. (1995)] and not to the depletion of GlcCer. This cannot be the reason for the disruption of axonal growth observed in hippocampal neurons, because exogenously added ceramide does not disrupt growth, and ceramide must be metabolized to GlcCer to support growth.

In summary, we have shown that ceramide can play distinct roles in the same neuron, depending on its concentration and on the stage of neuronal development. As a second messenger, ceramide presumably acts at the level of the plasma membrane in transducing external signals, but as a possible regulator of intracellular transport, ceramide must be metabolized to GlcCer in intracellular membranes (Futerman, 1994). Future studies will need to address the regulation of the enzymes of SL synthesis and degradation during neuronal development.

\section{REFERENCES}

Bielawska A, Crane HM, Liotta D, Obeid LM, Hannun YA (1993) Selectivity of ceramide-mediated biology-lack of activity of erythrodihydroceramide. J Biol Chem 268:26226-26232.

Bligh EG, Dyer WJ (1959) A rapid method of total lipid extraction and purification. Can J Biochem Physiol 37:911-917.

Boldin S, Futerman AH (1997) Glucosylceramide synthesis is required for basic fibroblast growth factor and laminin to stimulate axonal growth. J Neurochem 68:882-885.

Chen CS, Rosenwald AG, Pagano RE (1995) Ceramide as a modulator of endocytosis. J Biol Chem 270:13291-13297.

de Chaves EP, Vance DE, Campenot RB, Vance JE (1995) Axonal synthesis of phosphatidylcholine is required for normal axonal growth in rat sympathetic neurons. J Cell Biol 128:913-918.

Deitch JS, Banker GA (1993) An electron microscopic analysis of hippocampal neurons developing in culture-early stages in the emergence of polarity. J Neurosci 13:4301-4315.

Dobrowsky RT, Werner MH, Castellino AM, Chao MV, Hannun YA (1994) Activation of the sphingomyelin cycle through the low-affinity neurotrophin receptor. Science 265:1596-1599.

Dotti C, Simons K (1990) Polarized sorting of viral glycoproteins to the axon and dendrites of hippocampal neurons in culture. Cell 62:63-72.

Dotti CG, Sullivan CA, Banker GA (1988) The establishment of polarity by hippocampal neurons in culture. J Neurosci 8:1454-1468.

Dotti CG, Parton RG, Simons K (1991) Polarized sorting of glypiated proteins in hippocampal neurons. Nature 349:158-161.

Dugan LL, Bruno VMG, Armagasu SM, Giffard RG (1995) Glia modu- 
late the response of murine cortical neurons to excitotoxicity: glia exacerbate AMPA neurotoxicity. J Neurosci 15:4545-4555.

Fishbein JD, Dobrowsky RT, Bielawska A, Garrett S, Hannun YA (1993) Ceramide-mediated growth inhibition and CAPP are conserved in Saccharomyces cerevisiae. J Biol Chem 268:9255-9261.

Fletcher T, Banker G (1989) The establishment of polarity by hippocampal neurons: the relationship between the stage of the cell's development in situ and its subsequent development in culture. Dev Biol 136:446-455.

Fletcher TL, Cameron P, de Camilli P, Banker G (1991) The distribution of synapsin I and synaptophysin in hippocampal neurons developing in culture. J Neurosci 11:1617-1626.

Furuya S, Ono K, Hirabayashi Y (1995) Sphingolipid biosynthesis is necessary for dendritic growth and survival of cerebellar Purkinje cells in culture. J Neurochem 65:1551-1561.

Futerman AH (1994) An update on sphingolipid synthesis and transport through the secretory pathway. Trends Glycosci Glycotechnol 6:143-153.

Futerman AH (1995) Inhibition of sphingolipid synthesis: effects on glycosphingolipid-GPI-anchored protein microdomains. Trends Cell Biol 5:377-380.

Futerman AH, Banker GA (1996) The economics of neurite growththe addition of new membrane to the growing axon. Trends Neurosci 19:144-149.

Goslin K, Banker G (1989) Experimental observations on the development of polarity by hippocampal neurons in culture. J Cell Biol 108:1507-1516.

Goslin K, Banker G (1991) Rat hippocampal neurons in low density culture. In: Culturing nerve cells, pp 251-281. Cambridge, MA: MIT.

Goslin K, Birgbauer E, Banker G, Solomon F (1989) The role of cytoskeleton in organizing growth cones: a microfilament-associated growth cone component depends upon microtubules for its localization. J Cell Biol 109:1621-1631.

Hannun YA (1994) The sphingomyelin cycle and the second messenger function of ceramide. J Biol Chem 269:3125-3128.

Hannun YA, Bell RM (1989) Functions of sphingolipids and sphingolipid breakdown products in cellular regulation. Science 243:500-507.

Hannun YA, Obeid LM (1995) Ceramide: an intracellular signal for apoptosis. Trends Biochem Sci 20:73-77.

Hannun YA, Obeid LM, Dbaibo GS (1996) Ceramide-a novel second messenger and lipid mediator. Lipid Second Messengers 8:177-204.

Harel R, Futerman AH (1993) Inhibition of sphingolipid synthesis affects axonal outgrowth in cultured hippocampal neurons. J Biol Chem 268:14476-14481.

Hirschberg K, Zisling R, van Echten-Deckert G, Futerman AH (1996) Ganglioside synthesis during the development of neuronal polarity: major changes occur during axonogenesis and axon elongation, but not during dendrite growth or during synaptogenesis. J Biol Chem 271:14876-14882.

Inokuchi J-I, Radin NS (1987) Preparation of the active isomer of 1-phenyl-2-decanoylamino-3-morpholino-1-propanol, an inhibitor of murine glucocerebroside synthetase. J Lipid Res 28:565-571.

Kolesnick R (1992) Ceramide: a novel second messenger. Trends Cell Biol 2:232-236.

Kroemer G, Petit P, Zamzami N, Vayssiere J-L, Mignotte B (1995) The biochemistry of programmed cell death. FASEB J 9:1277-1287.
Ledeen RW, Yu G (1992) Ganglioside function in the neuron. Trends Glycosci Glycotechnol 4:174-187.

Legler G (1977) Glucosidases. Methods Enzymol 46:368-381.

Lisanti MP, Rodriguez-Boulan E (1990) Glycosphingolipid membrane anchoring provides clues to the mechanism of protein sorting in polarized epithelial cells. Trends Biochem Sci 15:113-118.

Merrill AH, Liotta DC, Riley R (1996) Fumonisins: fungal toxins that shed light on sphingolipid function. Trends Cell Biol 6:218-223.

Oppenheim RW (1991) Cell death during development of the nervous system. Annu Rev Neurosci 14:453-501.

Pagano RE, Martin OC (1988) A series of fluorescent $N$-acylsphingosines: synthesis, physical properties, and studies in cultured cells. Biochemistry 27:4439-4445.

Pagano RE, Martin OC (1994) Use of fluorescent analogs of ceramide to study the Golgi apparatus of animal cells. In: Cell biology: a laboratory handbook (Cerlis JE, ed), pp 387-393. New York: Academic.

Paul P, Kamisaka Y, Marks DL, Pagano RE (1996) Purification and characterization of UDP-glucose: ceramide glucosyltransferase from rat liver Golgi membranes. J Biol Chem 271:2287-2293.

Pushkareva M, Obeid LM, Hannun YA (1995) Ceramide: an endogenous regulator of apoptosis and growth suppression. Immunol Today 16:294-297.

Radin NS, Vunnam RR (1981) Inhibitors of cerebroside metabolism. Methods Enzymol 72:673-684.

Raff M, Barres BA, Burne JF, Coles HS, Ishizaki Y, Jacobson MD (1993) Programmed cell death and the control of cell survival: lessons from the nervous system. Science 262:695-700.

Riboni L, Prinetti A, Bassi R, Caminiti A, Tettamanti G (1995) A mediator role of ceramide in the regulation of neuroblastoma Neuro2a cell differentiation. J Biol Chem 270:26868-26875.

Rosenwald AG, Pagano RE (1993) Inhibition of glycoprotein traffic through the secretory pathway by ceramide. J Biol Chem 268:4577-4579.

Rosenwald AG, Machamer CE, Pagano RE (1992) Effects of a sphingolipid synthesis inhibitor on membrane transport through the secretory pathway. Biochemistry 31:3581-3590.

Schwarz A, Futerman AH (1996) The use of anti-ganglioside antibodies to localize gangliosides in neurons of the central nervous system. Biochim Biophys Acta 1286:247-267.

Schwarz A, Rapaport E, Hirschberg K, Futerman AH (1995) A regulatory role for sphingolipids in neuronal growth: inhibition of sphingolipid synthesis and degradation have opposite effects on axonal branching. J Biol Chem 270:10990-10998.

Seufferlein T, Rozengurt E (1994) Sphingosine induces $\mathrm{p} 125^{\mathrm{FAK}}$ and paxillin tyrosine phosphorylation, actin stress fiber formation, and focal contact assembly in Swiss 3T3 cells. J Biol Chem 269:27610-27617.

Siegel G, Agranoff B, Albers RW, Molinoff P (1994) Basic neurochemistry, 5th Ed. New York: Raven.

Simons K, van Meer G (1988) Lipid sorting in epithelial cells. Biochemistry 27:6197-6202.

Wiesner DA, Dawson G (1996) Staurosporine induces programmed cell death in embryonic neurons and activation of the ceramide pathway. J Neurochem 66:1418-1425. 